\title{
The Natural Development of Argumentation as a Human Affair: A Fanciful History JoHN O. BurTis
}

SCTD Department, 129 Nichols Hall, Kansas State University, Manhattan KS 66506 U.S.A. Phone: (785) 532-6875 E-mail: joburtis@hotmail.com

Introduction: Students who take my Argumentation and Debate class typically carry one of two different pieces of luggage. Those with no training in informal logic, debate, or the systematic construction and analysis of arguments carry the first. Their lack of training is not the luggage they carry; it can, in fact, be a strength. But their tendency is to turn this lack of personal experience into a piece of psychological luggage that weighs them down. In particular, many carry the opinion with them that their lack of experience makes them less able than others to reason logically, think critically, or construct and critique arguments well. They find this initial attitude reinforced when a whole new language is presented in the form of talk about inductive reasoning, fallacies, debate terminology, and argument components and analysis.

The second set of students comes to the class with some formal training, usually in scholastic debate. The experience is not their luggage. However, many treat the ideas that result as accurate, when in some cases they are not; or as inclusive of the subject matter, when it never is; or as a laurel on which to rest, which inevitably results in lower than necessary scores on exams. The most problematic of these forms is when students reify their conceptions of the practices involved in argumentation and debate into God's truth or some lesser but still immutable conception. There is no sense, in such cases, that there was ever an evolution of thinking around how argument might best be accomplished. I want them to understand argument as a naturally evolving set of conventions/constraints that can help guide their thinking. Anything human has some history and is subject to change; that is where I begin my work.

For a number of years I began my class by attempting to introduce students to the nature (definitions; models) and component parts (claims; warrants; etcetera) of an argument. As a result of the luggage my students carry, I have recently shifted my approach. I now begin by talking about why, if we lived in a world that did not have the fundamentals of reasoning and of argument, we would have to invent them. This helps put all of the students, experienced, misguided, or otherwise, on a similar first footing. Then, over time in the class, we develop a system 
of reasoning and argument (and, when there is time, debate) that is considerably like the one that is traditionally taught in such a class. What follows is a brief orientation to this process, which includes the two exercises that $I$ have developed to get students onto that similar first-footing in their study of argument.

At or near the beginning of the semester, $I$ ask the students to consider a hypothetical, a sort of counter-factual: "What would the world look like without argument?" Assume people, but do not assume any systematic process for resolving disputes. What would that be like?

\section{Exercise 1:}

Working alone for 3-4 minutes, then, working in dyads for another 4-5 minutes, try to figure out what people would do when they encountered one another. You can imagine full grown adults (e.g., Adam and Eve as Mark Twain did in one humorous essay about their attempts to name things they encountered in the Garden) or, the first few homo sapiens, evolving out of the population of homo erecta and just tipping into the cranial capacity necessary to symbolize. There you have it, a world without any preconceived process or ability to resolve disputes symbolically. When these folks in your imaginings begin to talk, what do they talk about? Do they argue? What about? How do they decide who wins?

After students have completed the above, I give them several minutes to read the following brief essay that I have written as my answer to the same questions.

\section{Nearer the Beginning}

Nearer the beginning, there were people, and, people talk! They talk to coordinate their activities, to build their relationships, and to understand and explain themselves and "their" world. When people talk, they argue. They disagree: about what names different stuff should be called; about what different things are; about what stuff means; about what things are good or bad; about how many things there are; about what effect doing some things has on other stuff; about what things ought be done. It is natural to disagree. And, because people want to appear civilized (to fit in), people slowly developed "proper" ways for these disagreements to occur.

Argumentation is a concept, it does not exist in nature. It is a creation of people trying to make sense of their disagreements, trying to find ways to disagree well (to "win") in a manner that is socially responsible (does not lead to bloodshed or war; has mutually acceptable outcomes). Argumentation assumes that there are good ways and bad ways to disagree. Good ways involve making and carefully testing good arguments. Bad ways do not.

Debate is a concept, it does not exist in nature. It is a creation of people trying to make sense of disagreement about which of their arguments is superior. Using debate assumes that carefully contested arguments can produce a "winner" or better choice among them. 
There are many rules for doing argument and debate. And, as is the nature of rules, they change over time with the introduction of new ideas or practices or philosophies or personalities. The only constant about argumentation or debate is that everything that is controversial (and therefore subject to disagreement) is subject to arguing about and is, therefore, debatable. Debaters debate the nature of argument or of debate (meta-theoretical critiques), or the rules for doing an argument or debate (procedurals), or the ways of defining who wins a debate (judging paradigm), or the correct outcomes on a particular question (substantive arguments). None of these, however, is basic to the nature of argument.

In its simplest form, to do argumentation or debate requires beginning with disagreement. To do disagreement requires assuming agreement can occur (otherwise, might makes right). To find or test or conceptualize agreement we need to begin somewhere. Bishop Whately thought we ought to begin by giving some presumption to a status quo, and to build our arguments from there. (Some postmodern kritiks claim the world is so messed up that there ought to be a permanent presumption for change, for undoing the evil that humankind has wrought. But that is another story for another time.)

This is how many of our communication theories are developed. We begin by people communicating or disagreeing. They begin to re-use forms of communication or disagreement that seem to work particularly well for them. Over and over again these forms recur (usually because of utility, sometimes because of taste). Rules of thumb, which practitioners develop or learn from coaches (folks who have become particularly good at the recurring form or at convincing others that they are particularly good at it), are designed to refine and improve the quality of the communication that occurs. Over time, a philosophy that guides the proper use of the form will evolve as will an exemplar model that shows all the correct component parts (say, of a lucid argument, of a good debate). These components constitute a special theory of communication (Bormann, 1980). The special theory that concerns us in this class is: "Argumentation" and in a few weeks we will have described it more fully to you. But first, let's spend a little more time with what you already know about argumentation.

Discussion. When you were imagining a system without any symbolic means of resolving disputes, you may have found, as our ancestors did at times that "might makes right." This doctrine, called "justicing" predates any sense of "justice" as we know it today. It took time for humans to figure out that winning through bloodshed is something other than the smiling of the gods on the triumphant-that there might be such a thing as rights and that anyone ought give a damn about the weak or the innocent. Once those complicated thoughts started to get worked on, there must have been early attempts to resolve disputes by talking. Indeed, even physical "warfare" had many early components of symbolic dispute resolution, including taking the honor from an opponent (counting coup) by touching him in battle (instead of cutting him open), the use of symbolic behaviors or paints 
to depict strength, and perhaps even sport. Kennedy (1998) points out that most animals have this "symbolic," "rhetorical" stage to their dispute resolution. It is not too long a trip (though it is taking eons) from restraint of any sort to figuring out how to run the whole dispute symbolically - through an argument, instead of a physical fight.

More fundamental even than the basic components of argument, which we will discuss later, is the assumption that argument can be useful to resolve disputes. If it is to act as such a tool, however, it needs to have the ability to provide resolution. There must be rules or conventions regarding how an argument happens so that those involved in the argument can determine its victor.

Some basic nomenclature is helpful at this point. For argument to happen there must be something about which to argue. This something is some current state of affairs (e.g., some current way of doing things; some current conception or theory regarding the nature of things; some current belief system). We need a name for this basic thing, this, current state of affairs:

(1) Status Quo [ST] = the current system.

There, that wasn't too hard. We conceived of a current state of affairs, then we named it: the status quo. We still do not have an argument though. The next thing that is necessary is controversy. Someone must be upset about the current state of affairs. Someone must want to argue for a change of the status quo in order for there to be an argument.

(2) Controversy $=$ opposing sides with somewhat equal access to the means and ends of truth finding.

To some extent at least, these sides need an equal opportunity to prevail or there is little to be accomplished by the argument. For instance, you would just pick the correct answer without an argument if there is no controversy because one side is obviously correct (e.g., Hitler did bad stuff). Or, you would not bother to have an argument at all if nobody cared which side was correct (e.g., the bicycle is superior to the vest).

(A) Affirmative $=$ the person or side that wants to argue or support or affirm the importance of doing or thinking something different than the status quo.

(B) Negative $=$ the person or side who wants to refute or disagree with or negate that difference.

If you have ever been in the mood for a good argument and found that nobody around you was interested in engaging you on the subject, you can appreciate the need for controversy. Even if you argue both sides yourself, you need some point of controversy to sustain argument construction and analysis.

Perhaps the first arguments required nothing more than a status quo and a criticism of it. Soon though, since the purpose of argument arising in nature is to provide resolution without bloodshed, the lack of adequate resolution would be- 
come evident if we just had these first two components. A third component concept is necessary before we can fully evolve a system of argument and before we can try to break arguments down into their constituent parts for analysis. This third concept allows us to start and to resolve an argument even when there is no clear idea about which is the better side. We can still proceed in such a case, by presuming, for the sake of the argument, that one side or the other is correct until its opponent side is demonstrated to be superior.

(3) Presumption = the status quo is "innocent" until proven guilty; SQ is correct until proven otherwise.

Whately' said presumption should be identified; then, like a fortress it must be attacked for it to be overturned. Traditionally, in debate, presumption is with the Negative. In baseball, presumption is with the offense because "A tie goes to the runner." In court, presumption is with the defendant (in the United States) who is presumed innocent until proven guilty. $^{2}$

In this sense, presumption is both a means of telling us who has to start the argument and of helping with uncertain outcomes. The one who advocates the change must always begin the debate. When the debate is over, if there is no clear winner, whoever is closer to the current system wins because presumption is with the Status Quo.

We are now ready for an argument to serve its useful purpose as a tool to help folks avoid bloodshed. We need to note, however, that one more concept has arisen concurrently with the development of presumption; for once one side is presumed to be true, the other side in the controversy immediately gets the burden to prove that their conceptions are true instead.

(4) Burden of Proof = the need to provide a strong enough argument to overcome presumption in favor of the opposing viewpoint. This burden goes to the negative once presumption goes to the affirmative.

These concepts may seem foreign to you now but they are not. In fact, they are names for fundamental parts of your own reasoning process, whether you know it or not. In particular, anything that you know about yourself or about the world in which you live can be organized and tested using these concepts. It doesn't take an expert to do it either. You can do it yourself. In fact, the following exercise will lead you through the process. After you have completed it, we will come back to the concepts of status quo, presumption, and burden of proof to organize what you have taught yourselves about these concepts. 


\section{Exercise2: HowDoUKnow}

- On the space to the right of it, write a single thought you have, a single thing you know, about each of the following. For each of the following,

What do you know?:

(1) Ice:

(2) Mathematics:

(3) Learning a foreign language:

(4) Getting someone to go out with you on a date:

(5) Who should be the next president of the U.S.A:

(6) Smoking tobacco:

(7) Using groups to make decisions where you work or in class:

(8) Buying clothes:

(9) Getting a suntan:

(10) Raising children:

(11) Brushing your teeth:

(12) Lying:

(13) Free speech:

(14) Staying healthy:

(15) Ford trucks:

(16) Children under 12 in pornographic movies:

(17) Your intelligence:

(18) Violence on television:

(19) Use of national achievement standards in high school:

(20) Good nutrition:

(21) How to act in an elevator:

(22) What to eat on Thanksgiving:

- How did you come to know that what you wrote down above is true? Did someone tell you? Did you watch something for awhile and figure it out yourself? Write down the answer to this question for each of the above items on the back of the page with the number of the item preceding the answer. For instance: (1) I learned that ice is stronger than tooth enamel when I chipped my tooth crunching my ice at Sonic.

- How certain are you that each cognition you recorded above is correct? On a scale of 1 to 7, with 1 being "Not Very Certain at All" and 7 being "Extremely Certain," rate how certain you are on each of the above. Put your Certainty Number rating (C) next to the item number. For instance: (1) C $=6$.

- How hard would it be, on each of the above cognitions, to get you to change your mind? On a scale of 1 to 7, with 1 being "Not Very Hard at All" and 7 being "Extremely Hard," rate how hard it would be for someone to convince you that your knowledge is wrong. Put your "hard to prove me Wrong "(W) number on the other side of the item number. For instance: $\mathrm{W}=7$ (1). 


\section{Debriefing HowDoUKnow}

Epistemology, the study of the nature of knowing, is an essential philosophical issue involving what we count as knowledge and how we decide to construct arguments. Different epistemological assumptions produce different kinds of debate practices. We will demonstrate this more during the last half of the semester but for right now we can use this exercise to help you get more in touch with your own epistemological processes. How do you know what you know? Well, first, what do you know?

The first question, What do you know? helps you start to describe your own personal status quo. Remember, status quo $=$ the present system or, in the case of this exercise, what you know/think to be the case. In policy debate we typically deal with groups of people where status quo is their governing structures, but it could just as easily be a predominant or personal ideology.

The second question, How do you know? introduces you to a variety of processes you have for knowing. You know many things because an authority (parent, teacher) or someone in your peer group told you so. In addition, your own experience and reasoning processes are the source of some of your knowledge. And, finally, you know some things because in your culture or religion or family, things have always been that way.

The third question, How certain are you? is about presumption and certainty. Remember, presumption is the agreement, for the sake of argument, that the status quo is correct until proven not to be. Presumption is held with greater or lesser certainty, depending on the cognition in question. And, the greater the certainty that the status quo is not flawed in a particular way, the greater the presumption against changing it. For instance, you have more presumption against giving away all of your money than you have against making a small contribution to charity.

The fourth question, How hard would it be to change? raises the issue of burden of proof. One who advocates a change in thinking must make an argument in favor of that change. We do not make changes willy-nilly in our status quo. We require an argument be made that includes a claim and warrant before we will even consider change. The more strongly held the cognition is that the advocate is attacking, the greater the burden of proof that will be required to overturn it.

We will further unpack the concepts found in these two exercises later in the course. In summary of this introduction, however, we have argued that it is natural that argumentation be developed as a system for allowing a particular kind of human interaction to proceed without bloodshed. Argumentation has its base in the recurring efforts we each make to know about our world and to test that knowledge. These basics are used as we attempt to increase the level of certainty we can have regarding our conclusions through the use of reasoning and scholarly research methodologies. Later we will also study how post-modern kritiques of the search for certainty can still be understood by going back to these fundamentals of argument. 


\section{References:}

Bormann. E.G. (1980). Communication theory. New York: Holt, Rinehart \& Winston. Kennedy, G.A. (1998). Comparative rhetoric: An historical and cross-cultural introduction. Oxford: Oxford University Press.

\section{Endnotes:}

'A simplified synopsis: Whateley, Richard (1787-1863). A bishop of the Anglican Church who taught at Oxford. See Elements of Logic, (1826); Elements of Rhetoric, (1828); and, Historical doubts concerning Napoleon Bonaparte. Whateley introduced the concept of presumption to rhetoric. He borrowed it from the law where guilt or innocence could be presumed. Where presumption lies dictates who has the burden of proof. Whately helped explain by using the (scientific) methods aimed at debunking Christianity to show with equal certainty that one could discredit the existence and significance of Napoleon. He argued that Christendom had presumption in Europe because it had won that status over the previous one and a half millennia. That presumption, then, had to be overturned by those who were using science to deny Christianity.

${ }^{2}$ Except, of course, in tax court where the IRS for years put the burden on U.S. citizens to prove their innocence.

\section{Debate for Philosophy and Critical Thinking Courses SCOTT STRoud}

Assistant Director of Forensics at the University of the Pacific

Graduate student in communication

1125 South Quincy Rd., Turlock, CA 95380 U.S.A.

Phone: (209) 946-1021 E-mail: ss0010@uop.edu

Many of the integral features of courses such as introduction to philosophy, ethics, logic, and critical thinking require actual practice in discourse situations to be truly retained. Yet, many classes are taught from the monologic point of lectures on the subject matter and individual evaluation of argument. Classes such as those mentioned above can benefit greatly from utilizing debates in class to put the skills taught into practice in a controlled, monitored discourse situation. This paper shares my experiences of how to conduct time-efficient and skill-effective in-class debates. I draw on my nine years of debate competing, judging, and coaching experience in indicating what has worked for me and what has not worked. The classes in which I have used this debate format are two general education classes, closely resembling "Introduction to Philosophy/Timeless Questions" and "Public Argumentation." This paper will discuss some debate basics, in-class logistics, and some instructor warnings. 